\title{
A mulher e o "fazer ciência": uma análise de filmes de comédia no ensino farmacêutico
}

\section{Women and "making science ": an analysis of comedy films used in pharmaceutical education}

\author{
Lêda Glicério Mendonça1, 1,3 \\ Lucia de La Rocquel \\ ${ }^{1}$ Instituto Oswaldo Cruz, Fundação Oswaldo Cruz, \\ Programa de Pós-graduação Stricto Sensu em \\ Ensino em Biociência e Saúde. Rio de Janeiro-RJ, \\ Brasil. \\ ${ }^{2}$ Instituto Federal de Educaçãa, Ciência e \\ Tecnologia do Rio de Janeiro, Curso de Farmácia \\ e de Especialização em Educação e Divulgação \\ Científica. Rio de Janeiro-RJ, Brasil. \\ ${ }^{3}$ Universidade de Coimbra, Faculdade de \\ Letras, Programa de Doutoramento em Estudos \\ Feministas. Coimbra - Portugal. \\ Correspondência / Correspondence \\ Lêda Glicério Mendonça \\ leda.mendonca@ifri.edu.br
}

\section{Resumo}

$\mathrm{O}$ artigo busca entender a representação das mulheres, e sua ausência no campo científico, em cinco filmes de comédia que foram utilizados como subsídio para um estudo de caso em apoio ao ensino de Deontologia Farmacêutica. Os filmes selecionados foram: "O inventor da mocidade" (1952), "O professor aloprado" (1963), "Junior" (1994), "O professor aloprado" (1996) e "Sem sentido" (1998). Os filmes foram centrados em experimentos com substâncias terapêuticas, nos quais o cientista responsável pela pesquisa era sempre um homem. Durante a apresentação da resolução do estudo de caso observou-se que, mesmo a maioria dos alunos sendo mulheres, estas não percebiam tal fato, salvo quando alertadas. Isso pode indicar que potenciais cientistas percebem como natural a menor representatividade da mulher nas ciências. O caminho encontrado para balizar a discussão repousa na crítica feminista cinematográfica denominada "Male gaze" e em outros referenciais nas relações de tecnociências. A análise dos filmes demonstrou que, apesar de produzidos em um intervalo de 46 anos, neles as mulheres foram retratadas de forma passiva e excluídas dos espaços de destaque por mecanismos de hierarquização e opressão. Assim, o cinema de comédia pode contribuir na formação humanística, almejada pelas atuais Diretrizes Curriculares Nacionais de Farmácia, com atenção especial voltada para conscientizar a categoria de que o posto de cientista do medicamento é também de protagonismo da mulher farmacêutica.

Palavras-chave: Ensino Farmacêutico. Cinema de Comédia. Crítica Feminista. Ciência e Arte. Male Gaze. 


\section{Abstract}

This paper discusses the representation of women in five comedy films and the absence of women in the scientific field; these films were used as subsidies for a study case used in support of Deontology teaching. The films selected for this case study were: "The monkey business" (1952); "The Nutty Professor" (1963); "Junior" (1994); "The Nutty Professor" (1996) and "Senseless" (1998). The films were centered around experiments with therapeutic substances, in which the scientist responsible for the research was always a man. When the resolution of the case study was presented to students, even though most of them were women, they did not realize this situation except when they were made aware of it. This shows that even potential scientists perceive the underrepresentation of women in science as natural. The feminist concept within film critique, called "Male gaze", and other references for techno-scientific relations were used as a basis for the debate. The analysis of the films showed that although they have been produced within a timeframe of 46 years, women were still portrayed as passive and were excluded from important positions by hierarchization and oppression mechanisms. Thus, comedy films can contribute to humanistic education, which is a goal of the current National Curriculum Guidelines for Pharmacy, particularly focused on making students aware that drug development is also a role to be played by women pharmacists.

Key words: Pharmaceutical Education. Comedy Film. Feminist Criticism. Science and Art. Male Gaze.

\section{Introdução}

Este artigo tanto busca entender os mecanismos que relegaram a mulher ao segundo plano do fazer ciência, quanto se volta para essa representação em cinco filmes de comédias hollywoodianas que foram utilizados em apoio a um estudo de caso aplicado no ensino de Deontologia Farmacêutica.

A Deontologia é o elenco de determinações objetivas, instruções operacionais e de cunho prático, que os membros de um grupo profissional devem seguir no exercício de suas atividades, para garantir a uniformidade, em todos seus aspectos e lugar, do trabalho e ação do grupo, como se fosse a ação de um único indivíduo. ${ }^{1} \mathrm{O}$ objeto principal do ensino da Deontologia, portanto, é problematizar a aplicação das leis referentes à conduta do profissional, mas não deve se restringir a isso. Precisa ir além e trazer à tona a reflexão sobre os princípios éticos. O aluno deve entender 
a diferença entre ética e moral, entre dever e direito, entre direito individual e coletivo, entre as diferenças de classe, etnia, gênero e cultura, para poder pensar em sua futura conduta profissional e suas implicações na sociedade.

Os filmes selecionados para o estudo de caso foram: "The monkey business" - O inventor da mocidade (1952); "The nutty professor" - O professor aloprado (1963); "Junior" - Júnior (1994); "The nutty professor" - O professor aloprado (1996) e "Senseless" - Sem sentido (1998).

Embora o primeiro foco do uso desses filmes em sala de aula fosse suscitar discussões acerca das situações que envolvem a experimentação com substâncias terapêuticas e todo o arcabouço legal que isso demanda, ficou evidente, no momento de pré-seleção dos filmes, que nos enredos as mulheres se encontravam em posição subalterna em relação aos homens, sobretudo no ato do "fazer ciência". Essa circunstância motivou a reflexão que ora se apresenta e não deve ser desvinculada das discussões sobre a conduta ética do profissional farmacêutico. Outras questões apareceram ao longo da aplicação da prática pedagógica, mas o foco deste trabalho foi a discussão das relações de gênero.

A mulher em filmes é geralmente representada segundo uma estereotipia, remetendo necessariamente para fenômenos de categorização, que também podem ser objeto de análise enquanto elementos de representação social. ${ }^{2}$ Arruda ${ }^{3}$ faz interessante paralelo conceitual entre as Teorias das Representações Sociais (TRS) e o Feminismo, já que ambas destinam-se revelar e/ou conceituar aspectos de objetos até então subvalorizados pela ciência, considerados como menores (a mulher e o senso comum), desmistificando esta hierarquização. Dessa forma, uma se municia da outra quando se trata de analisar a representação da mulher em contextos variados.

As mulheres estão nos filmes para completar o sentido das histórias e aparecem, na maioria das vezes, em atitude passiva em relação aos acontecimentos e como "objetificação" do desejo masculino. As tramas principais estão no caso dos cinco filmes, apoiadas na personagem masculina. Muitos são os argumentos da crítica feminista para analisar e explicar essa situação. A teoria feminista do cinema teve e tem grande importância tanto nos movimentos feministas como nos estudos cinematográficos, fundando uma nova perspectiva de análise cujas abordagens acompanham os questionamentos e os estudos de gênero. ${ }^{4}$

Nos Estudos Feministas, há muitas abordagens teóricas para se discutir a representação da mulher em expressões artísticas, tais como: identificar os modos como a "feminilidade" é evidenciada na representação; criar ou transformar estruturas hierárquicas de dominação; produzir uma prática cultural que resista ao posicionamento da mulher como espetáculo, ou objeto do male gaze $e^{5}$ estes dois últimos são os pontos de maior interesse no presente texto. No que diz respeito à exclusão da mulher na ciência, é possível pensar nas estruturas hierárquicas de dominação e quanto à representação das mulheres passivas, leva-se em conta a "mulher como espetáculo" in male gaze. 
Quanto à exclusão da mulher na ciência, vários são os trabalhos que esmiúçam o tema. Há os que buscam estatísticas para demonstrar a desigualdade; ${ }^{6-8}$ os que tratam do determinismo biológico que considera as mulheres incapazes de realizar tarefas de raciocínio lógico, o que teria sido relacionado, ao longo dos tempos, ao fato de serem vistas como homens falhos, terem cérebros menores ou por conta das funções reprodutivas que, consequentemente, desviariam o tempo de estudo para o cuidado com a prole. ${ }^{9-11} \mathrm{E}$ há uma construção histórica que reforça a hierarquização entre os sexos e a subalternidade da mulher.

$\mathrm{Na}$ atualidade, ainda sentimos os reflexos da Grécia Antiga em relação às concepções filosóficas das representações do feminino, que levaram a pensar o feminino como derivado e, consequentemente, as mulheres como o segundo sexo, ao longo de toda a tradição ocidental. ${ }^{12}$ Há um pensamento predominante, inclusive que a mulher no mundo capitalista moderno ainda não é dona de seu próprio corpo e mente, e quando isso ocorre é sob grande risco. ${ }^{13}$

Outras questões ainda explicam a exclusão da mulher no campo científico ou na academia. No início da década de 1980, Margaret Rossiter propôs dois conceitos que ampliam o sentido do fenômeno do teto de vidro (glass ceiling): a segregação hierárquica, fenômeno pelo qual, conforme se sobe a escada do poder e prestígio, cada vez menos mulheres são vistas, e a segregação territorial, fenômeno no qual as mulheres tendem a se agrupar em áreas com menos prestígio e menor remuneração, atribuições relacionadas com o cuidado ao outro e que replicam as tarefas do lar, tais como o magistério, a enfermagem e a nutrição. ${ }^{9}$

O fenômeno chamado de "teto de vidro" se caracteriza pela ascensão profissional da mulher até determinado ponto. Quando ela atinge cargos mais altos, de maior visibilidade ou posição de tomada de decisão, há uma barreira invisível que impede que ela suba. Há, no entanto, o contrário disso, que aumenta mais ainda a desigualdade: é o fenômeno chamado glass escalator (escada rolante de vidro), situação em que os homens progridem mais depressa e com menos qualificação do que as mulheres, especialmente em áreas onde há predomínio feminino. ${ }^{14}$

No que diz respeito à "mulher como espetáculo" há, nesse campo, um movimento importante evocado por Mulvey ${ }^{15}$ e ampliado por Kaplan, ${ }^{16}$ que repousa na crítica feminista cinematográfica e analisa a representação da mulher tomando como apoio a psicanálise freudiana e lacaniana. Elas defendem o fato de que as mulheres são representadas, em sua maioria, de forma erotizada, em atitude passiva, sob um olhar masculino - male gaze.

Sobre o male gaze, Laura Mulvey afirma que a mulher é representada em dois níveis: como objeto erótico inerente ao próprio roteiro, e como objeto erótico para o olhar do espectador, compartilhando um tensionamento dos dois lados da tela. Ann Kaplan ${ }^{16}$ sinaliza que "nos filmes de Hollywood é negada à mulher uma voz ativa e um discurso. Em silêncio, elas vivem vidas frustradas ou, se resistem a essa condição, sacrificam as próprias vidas por tal ousadia”. 
Retornando aos filmes em questão, as mulheres assumem posição secundária em relação aos protagonistas masculinos. Dos cinco filmes citados, o único que não segue esse padrão de forma tão clara é Junior, em que há uma inversão de papéis sociais biologicamente determinados. Os filmes apresentam um gradativo aumento da participação da mulher no campo profissional de acordo com a cronologia em que eles foram produzidos e concebidos. Entretanto, na maior parte dos filmes permanece a erotização da imagem feminina. Por isso, a análise será dividida em períodos históricos temporais: O inventor da mocidade (1952) situado no pós-guerra; O professor aloprado (1963), no período da Guerra Fria; e Júnior (1994), O professor aloprado (1996) e Sem sentido (1998), nos anos 1990, era de grandes avanços tecnológicos e do colapso do comunismo. ${ }^{17}$

Fazendo um paralelo temporal de como as mulheres foram retratadas nos filmes na perspectiva das teorias feministas, cabe salientar que a ficção reflete os comportamentos e pensamentos praticados na realidade: $O$ inventor da mocidade (1952) foi filmado na transição entre a primeira geração do feminismo (Feminismo de Primeira Onda ou Primeira Vaga), que representou o surgimento do movimento feminista, que lutava pela igualdade de direitos civis, políticos e educativos, reservados apenas aos homens, e a segunda geração (Feminismo de Segunda Onda ou Segunda Vaga). O professor aloprado (1963) foi produzido na segunda fase do feminismo, surgido nas décadas de 1960 e 1970, em especial nos Estados Unidos e na França. As feministas americanas enfatizavam a denúncia da opressão masculina e a busca da igualdade; os filmes Júnior (1994), O professor aloprado (1996) e Sem sentido (1998) foram exibidos no Feminismo de Terceira Onda ou Terceira Vaga, cuja proposta se concentra na análise das diferenças, da alteridade, da diversidade e da produção discursiva da subjetividade. ${ }^{18}$

\section{A percepção da imagem da mulher pelos expectadores e por elas mesmas}

O uso de cinema de comédia em aporte ao ensino de Deontologia Farmacêutica nesse contexto já vinha sendo praticado desde 2008. Com o passar do tempo, percebeu-se que os alunos, ao exporem os resultados do estudo de caso, se restringiam unicamente a responder ao roteiro proposto, provavelmente pelo pouco tempo destinado à disciplina (30 horas/aula) em comparação à carga horária total do curso (5.103 horas/aula).

A prática pedagógica aqui apresentada foi conduzida em quatro turmas, duas no ano de 2012 (aqui denominadas 1-2012 e 2-2012, respectivamente) e duas no ano de 2013 (aqui denominadas 1-2013 e 2-2013, respectivamente). Os cinco filmes foram assistidos pelas quatro turmas conforme exposto na tabela 1 . 
Tabela 1. Cronograma de aplicação do estudo de caso tomando como base os filmes de comédia

\begin{tabular}{c|c|c|c|c}
\hline Título do filme & $\begin{array}{c}\text { Turma } \\
\mathbf{1 - 2 0 1 2}\end{array}$ & $\begin{array}{c}\text { Turma } \\
\mathbf{2 - 2 0 1 2}\end{array}$ & $\begin{array}{c}\text { Turma } \\
\mathbf{1 - 2 0 1 3}\end{array}$ & $\begin{array}{c}\text { Turma } \\
\mathbf{2 - 2 0 1 3}\end{array}$ \\
\hline O inventor da mocidade & & $\mathrm{x}$ & $\mathrm{x}$ & \\
\hline Professor aloprado (1963) & & & $\mathrm{x}$ & $\mathrm{X}$ \\
\hline Júnior & $\mathrm{x}$ & $\mathrm{x}$ & $\mathrm{x}$ & \\
\hline Professor aloprado 1996 & & & $\mathrm{x}$ & $\mathrm{x}$ \\
\hline Sem sentido & $\mathrm{x}$ & & $\mathrm{x}$ & $\mathrm{x}$ \\
\hline
\end{tabular}

As turmas em que os filmes foram exibidos eram constituídas da seguinte maneira: turma 1-2012 - 28 alunos (3 homens e 25 mulheres); turma 2-2012 - 9 alunos (2 homens e 7 mulheres); turma 1-2013 - 33 alunos (4 homens e 29 mulheres); turma 2-2013 - 13 alunos (3 homens e 10 mulheres). Esses números demonstram que as turmas são majoritariamente femininas.

Os alunos, ao apresentarem a resolução de seus estudos de caso, subsidiados pelos enredos dos filmes, não se estendiam para temas que são evidentes nos filmes, tais como: por que o cientista que experimenta as substâncias terapêuticas não é farmacêutico? Por que as mulheres não têm participação decisiva nos acontecimentos? Por que o experimento não é conduzido por uma mulher?

Essas questões sempre eram levantadas pela docente após a apresentação dos alunos, ampliando as discussões inerentes à disciplina, sendo as duas últimas perguntas as de maior interesse neste trabalho. Infelizmente, pelo fato de a disciplina contar com pequena carga horária em relação ao total do curso, os alunos geralmente se detinham a responder ao roteiro do estudo de caso, sem tempo suficiente para uma reflexão mais apurada ou discussão ampla. O que causou estranheza foi o fato de que, mesmo havendo 71 mulheres num universo de 83 alunos, nenhuma delas se deu conta de que o experimento não tinha sido conduzido por mulher alguma ou ao menos questionaram isso.

Dados fornecidos pela Federação Nacional dos Farmacêuticos extraídos em meados de 2012 apontam que, naquele momento, havia cerca de 370 mil farmacêuticos inscritos e ativos no Brasil, e que as mulheres representavam $70 \%$ desses profissionais. ${ }^{19}$ A partir do momento em que a situação era exposta pela docente, os alunos se davam conta. Isso nos sugere que a situação é tão entronizada em um coletivo social, que a ausência feminina na ciência já está naturalizada, faz parte do senso comum, que se reflete na ficção e nas mídias, retornando por sua vez ao público, fechando assim, um "círculo vicioso". 
Mulvey ${ }^{15}$ e Kaplan ${ }^{16}$ criticam o cinema narrativo clássico, considerando que este explorou a mulher como objeto erótico a ser contemplado pelo olhar masculino. Mulvey ${ }^{15}$ relata que o que a levou a interpretar a representação erotizada e passiva da mulher nos filmes hollywoodianos foi a participação em um grupo de leitura sobre a psicanálise freudiana, pois Freud elaborou teorias sobre a sexualidade da mulher embasadas em princípios de uma sociedade patriarcal. Ela se apropriou, então, de conceitos freudianos como a escopofilia e o voyeurismo, para tentar entender o male gaze.

A psicanálise é utilizada não só para aprofundar uma análise cinematográfica, mas a análise de um discurso dominante falocrático embasado em uma diferença sexual que sustenta a verdade de toda a ciência, a lógica de todo o discurso. A mulher funciona como "o outro", sem voz que só existe e é representado pelo masculino. ${ }^{20} \mathrm{O}$ "outro", o "diferente" é considerado um ser falho, e por isso sem voz ou iniciativa para tomar a frente das decisões.

Kaplan centrou seu trabalho na análise de filmes produzidos em Hollywood, demonstrando amplamente as formas pelas quais os mitos patriarcais funcionam para situar a mulher como silenciosa, ausente e marginal. Mesmo que os filmes mencionados neste trabalho tenham sido produzidos em três espaços temporais distintos, a passividade e a subalternidade feminina persistem, conforme será visto a seguir.

\section{0 pós-guerra e a "rainha do lar"}

O primeiro filme a ser aqui abordado é O inventor da mocidade (1952), produzido poucos anos após o término da Segunda Guerra Mundial. O contexto social do período da guerra fez com que houvesse a necessidade da mão de obra feminina na esfera do trabalho, em substituição aos homens que foram para a frente de batalha. Com o término da guerra, os homens que sobreviveram retornaram a seus postos de trabalho, reativando a ideologia que valorizava a diferença de papéis por sexo, conferindo o espaço doméstico à mulher.

O acesso das mulheres ao campo científico nos Estados Unidos ainda foi dificultado com uma lei que franqueava os estudos em ciclos superiores com pagamento de pensões vitalícias aos veteranos de guerra. ${ }^{9}$ Somado a isto, o capitalismo americano do pós-guerra, com sua promessa de prosperidade e consumo de bens duráveis popularizou o American way of life, que reforçava a imagem da mulher como a rainha do lar nas mensagens veiculadas pela mídia, inclusive no cinema. Esse retrocesso acabou fazendo com que surgisse um novo tipo de feminismo nos anos seguintes, o Feminismo de Segunda Onda ou Vaga ${ }^{4}$, que lançava a luta das mulheres para um maior espaço na sociedade. 
Para melhor entendimento, é exposto a seguir o enredo do filme: Dr. Fulton (Cary Grant), casado com Edwina (Ginger Rogers), é pesquisador da Oxly indústria química e trabalha desenvolvendo e testando em macacos um produto que pretende funcionar como elixir da juventude intitulado "B-4". Um dia uma macaca se solta do cativeiro e aleatoriamente mistura substâncias, criando o produto tão desejado. Acidentalmente, a mistura feita pela macaca é derramada no bebedouro do laboratório e todos da empresa bebem da água contaminada, experimentando todo o tipo de efeito e confusões.

É interessante notar que no filme O inventor da mocidade, as mulheres estão totalmente excluídas do espaço científico e de decisões. No laboratório em que o experimento é conduzido, só trabalham homens. A ideia colocada no filme é de que Dr. Fulton, caso descobrisse a fórmula da juventude, seria aspirante a ganhar um Prêmio Nobel. Buscando referências históricas, ${ }^{8}$ quando se fala de uma ciência masculina, um razoável indicador poderia ser o número muito pequeno de mulheres que ganharam o Nobel. Elas são apenas 16 entre os laureados das Ciências (duas em Física, quatro em Química e dez em Medicina e Fisiologia; destas 16, apenas três são exclusivos de mulheres).

No filme existem duas personagens femininas que auxiliam na trama. Uma delas é Edwina Fulton, esposa do cientista, ator principal da trama. A outra é Lois Laurel (Marilyn Monroe), secretária do dono da Indústria Química Oxly. A primeira, Edwina, é representada como a "rainha do lar" e vem sempre em auxílio do marido. Mesmo que ela tenha sólida formação em Ciências, o que fora conveniente para preparar a mulher de um grande cientista, não exerce a profissão, ficando restrita às atividades domésticas e a ajudar ao marido no que for necessário. A outra personagem, encarnada por Marilyn Monroe, é representada de maneira erotizada, já que apenas seus atributos físicos são evidenciados; sua intelectualidade, pelo contrário, é a todo momento questionada.

Sobre Marilyn e o cinema hollywoodiano, Kaplan salientou que, nos anos 50, os filmes eram interessantes porque mostravam antigos códigos desmoronando. A sexualidade respingava por todo lado, sem ser, entretanto, reconhecida: nos anos 50, o medo da sexualidade parecia reprimido - e por isso mesmo transborda por toda a parte, especialmente em atrizes como Marilyn Monroe e Natalie Wood, em comparação com Marlene Dietrich, Lauren Bacal ou Rita Hayworth.

Tomando como base as personagens retratadas no filme, no que diz respeito a subalternidade e exclusão no campo científico, as mulheres sempre estiveram presentes no curso da humanidade, inclusive no campo das ciências, mas sua participação foi ora negada, ora apagada, pois eram criados mecanismos políticos, sociais e culturais que as categorizavam como incapazes para o desenvolvimento da atividade científica. ${ }^{21}$ No caso de Edwina, seria a pressão de sua condição social, foi educada de maneira adequada para apoiar seu marido cientista e seus atributos intelectuais deveriam ser utilizados apenas para a manutenção da sua família. No caso de Lois, por ter origem 
humilde, ela teria que se sujeitar a trabalhar para se manter, mas não teria condições de galgar posição de destaque no mundo do trabalho pelo fato de ser mulher. Restaria apenas, a posição subalterna de ser secretária.

Como na sociedade ocidental a mulher é encarada como o "outro", a diferença em si já estabelece e implica uma hierarquia, como é possível ver, por exemplo, na longa jornada das mulheres em busca da cidadania e autonomia econômica no século XX, nos Estados Unidos: pelo fato de não serem homens, muitas vezes eram e ainda são impedidas de galgar determinados postos de trabalho. ${ }^{13}$

\section{No auge da guerra-fria}

O segundo filme a ser tratado será $O$ professor aloprado, de 1963, que foi produzido e lançado na primeira metade da Guerra Fria, em que o planeta vivia um teórico estado de paz, mas uma preparação iminente para a guerra a eclodir entre Estados Unidos e União Soviética. Assim, no período em que se instalou a corrida armamentista, o exercício das profissões militares e científicas exigia "certa insanidade" para promover o desenvolvimento tecnológico que daria aporte à guerra sem que isso fosse abertamente revelado. ${ }^{22}$

Daí advém um período de incentivo à formação científica. Nos Estados Unidos, o Título VII da Lei de Direitos Civis (posteriormente reforçada pela Lei de Igual Oportunidade de Emprego, de 1972) proibia discriminação baseada em sexo na educação e emprego. Nesse frenesi tecnológico, muitas mulheres ganharam espaço no campo científico.

O cinema contemporâneo, é claro, foi muito mais longe que o cinema noir na representação explícita da sexualidade feminina. As causas que levaram a isso são bem conhecidas: os numerosos movimentos dos anos 60 produziram mudanças culturais radicais que afrouxaram os rígidos códigos puritanos.

A exibição ostensiva da sexualidade feminina tem sido uma ameaça para o patriarcado e exigido um nível muito maior de objetividade sobre as causas subjacentes ao fato de a mulher ter sido relegada à ausência, ao silêncio e à marginalidade... Os medos patriarcais não funcionam mais nessa era pós-60: a mulher sexual não pode mais ser taxada de "má", uma vez que adquiriu o direito de ser "boa" e sexual. ${ }^{16}$

Como a ficção reflete a vida real e a sociedade em que ela foi criada e não deixa de, por sua vez, também influenciá-las, há no filme uma liberalidade espontânea na sexualidade feminina. Há também maior participação das mulheres no campo acadêmico e no espaço decisório, praticamente numa relação de 1:1 entre homens e mulheres, o que é demonstrado tanto nas cenas em que aparece a sala de aula, como na sala do Conselho de Professores, onde homens e mulheres dividem em proporções iguais o mesmo espaço. 
Para melhor entendimento, será aqui exposto o enredo do filme: Dr. Kelp (Jerry Lewis) filho de uma mãe opressora (Edwina Kelp - Elvia Allman), é magro, franzino e desajeitado e professor de uma escola secundária. Ele se apaixona por uma aluna, Stella Purdy (Stella Stevans) e resolve experimentar em si mesmo um tônico que ele inventou e que o torna mais viril, para tentar conquistar a amada. A experiência proporciona momentos de Dr. Jekyl e Mr. Hyde ao Prof. Kelps.

Existem duas personagens femininas de maior relevo: uma é a doce estudante Stella Purdy, pela qual o professor se apaixona, e a outra é Edwina Kelp, a mãe repressora que foi implicitamente responsável pela criação do professor tão desajeitado e tímido.

A primeira, Stella, é aluna do Prof. Kelps. Angelical, ao mesmo tempo é sensual e experimenta a liberdade de frequentar a noite, beber e fumar em uma sociedade puritana do interior dos Estados Unidos. No filme, é retratada como estudante mediana, por vezes relapsa por ter a "cabeça nas nuvens" quando se apaixona por Buddy Love, a segunda personalidade do Prof. Kelps. O cinema continua tecendo muito mais aquela velha imagem da mulher que não usa o intelecto para fazer ciência. ${ }^{21} \mathrm{E}$ continua descrevendo a ideia já discutida por tantos outros teóricos feministas sobre os estereótipos sexuais, embasados em evidências biológicas, que associam aos homens as características de racionalidade, competitividade e objetividade, e às mulheres a passividade e emotividade. Tanto é assim que, na porção final do filme, Buddy Love diz que a ciência pode viver sem a contribuição de Stella e ela deixa os estudos para se tornar esposa e mãe, como cabe a redenção e salvação da mulher no sistema de domínio do patriarcado ocidental da época.

A segunda, Edwina Kelps, aparece pouco na trama. É a mãe opressora que é ríspida e autoritária com o Prof. Kelps e seu pai. Ela delega ao Sr. Kelps parte das tarefas domésticas e o destrata sempre que pode. Em dado momento, o pai do Prof. Kelps toma o tônico e tem sua masculinidade exacerbada, e passa a dominar a relação.

Nos dois casos, o que se observa é o modelo fetichista segundo o qual a mulher é diegeticamente controlada pelo matrimônio - ou quando não se submete ao modelo, deve ser punida, a femme fatale deve ser metaforicamente assassinada. "O revólver ou faca assumem o lugar do falo que deve, eliminando-a, dominá-la". ${ }^{16}$

\section{A era da crise e o feminismo crítico}

Os três últimos filmes foram produzidos na década de 1990. O mundo, nesse período, passou por muitas mudanças. Havia terminada a "Era de Ouro", em que muitos países haviam experimentado amplo crescimento econômico no Ocidente. Não só o comunismo ruiu, como o mundo capitalista também sofreu uma série de crises cíclicas entre 1980 e 1990. Por outro lado, o mundo experimentou um grande boom tecnológico, que trouxe mais conforto aos lares e diminuir os postos de trabalho, retroalimentando a crise. ${ }^{22}$ 
Os movimentos feministas foram se transformando ao longo dos anos 1970 - o feminismo da segunda onda, o da igualdade, que procura romper as barreiras que impedem às mulheres o acesso ao mundo público; em 1980 - o feminismo da diferença, que discute a sexualização; e em 1990 - o feminismo radical, que discute o fato de a ciência, a sexualidade e o gênero estarem desenhados de maneira dicotômica, tentando renegociar os processos hierarquizantes. ${ }^{23}$

Foi somente em 1970 que começaram a ser traçadas estatísticas para mensurar seriamente a participação das mulheres nas ciências nos Estados Unidos. Nesse país, no final dos anos de 1990, as mulheres constituíam 54\% dos diplomados em graduação (metade das quais graduadas em Ciências); a exclusão aparecia nos níveis de pós-graduação, em que apenas $40 \%$ dos doutorandos eram mulheres. ${ }^{9}$

Em países como o Brasil, por exemplo, o panorama acadêmico é melhor e a participação de mulheres na força total de pesquisadores é maior do que a média mundial, inclusive quando comparados a países com grande tradição científica. Esse ponto positivo, porém, contrasta com uma dura realidade: a violência urbana aumenta a mortalidade de homens em idade produtiva e as desigualdades sociais fazem com que seja relativamente fácil a uma mulher de classe média alta contratar uma empregada para substituí-la em seus afazeres domésticos, formando então outra rede de hierarquização, a social. ${ }^{11}$ No Brasil, mesmo que as mulheres estejam se preparando melhor para a vida profissional, elas continuam ganhando menores salários. ${ }^{8}$ Exemplificando numericamente, em um grupo de trabalhadores estudados por uma empresa de recursos humanos, 19,5\% das mulheres eram pós-graduadas, sendo a proporção entre os homens de 17,3\%. Um total de 44,2\% delas tem graduação, ante 38\% deles. Mesmo assim, elas recebem em média 40\% a menos do que eles.

É importante dizer que as mulheres retratadas nos filmes têm inserções diferentes no campo científico. Embora partilhem de maneira mais expressiva do espaço científico, continuam em cena apenas para completar a história, de maneira passiva, aguardando a ação ativa da personagem principal masculina, perpetuando o male gaze: uma é cientista renomada, líder de linha de pesquisa, com laboratório próprio no filme Júnior (1994); outra é professora de graduação que não desenvolve nenhum experimento ou qualquer outra atividade de relevância no filme $O$ professor aloprado (1996); a terceira é estudante de graduação mediana, no filme Sem sentido (1998).

A análise da política de representação de personagens femininas nos filmes de ficção tem sido uma preocupação central de muitas críticas feministas, e detectou a ausência de papéis femininos fortes que saíssem da visão patriarcal tradicional. ${ }^{24}$ É nessa perspectiva que serão descritas de maneira breve as personalidades femininas dos três filmes.

Outra questão interessante é que dois dos três filmes aqui abordados têm como base das experimentações a Engenharia Genética (Júnior e O professor aloprado); o experimento do filme Sem sentido é relacionado com as Neurociências. A imagem da ciência refletida no cinema reproduz o 
que é novidade ou pesquisa de ponta no momento em que as obras são concebidas; nos anos 1990, esses campos científicos alcançaram grande repercussão. Em geral, nos filmes a primeira parte explica as conquistas da ciência e, na continuação, os cientistas tentam fugir das consequências de suas descobertas/criações. ${ }^{25}$

\section{Tudo trocado num mundo performático}

Dos filmes abordados até então, o título Júnior (1994) talvez seja o que se afaste mais dos padrões de erotização e passividade da imagem da mulher no cinema, recaindo, porém em outro estereótipo bastante difundido: o do cientista solitário, desajeitado e desleixado com a aparência.

Para melhor entendimento cabe aqui o enredo do filme: Dr. Arbogast (Deni de Vito) e Dr. Hess (Arnold Schwarzenegger) trabalham em uma universidade, desenvolvendo o produto "Engravidol", que pode auxiliar as mulheres que sofrem de infertilidade a conceberem filhos. As autoridades governamentais da saúde vetam a continuidade dos testes e, consequentemente, a universidade cancela o financiamento da pesquisa. Frente a isso, os dois se veem obrigados a realizar a autoexperimentação no Dr. Hess, conseguindo a primeira gravidez masculina de que se tem notícia. Para tanto, eles roubam o óvulo de uma pesquisadora de criogenia, Dr. Diana (Emma Tompson), que passa a ser o pai da criança.

Frente ao enredo ora apresentado, muitas questões são trazidas à tona. Sobre a Bioética, que envolve a reprodução assistida; sobre a atribuição de comportamento, responsabilidades e papéis sociais demarcados pela questão reprodutiva; as relações de poder sobre a paternidade/ maternidade, prole e corpo. Há uma inversão de papéis sociais no binômio pai-mãe na história. Com isso, há duas figuras femininas a serem apreciadas, Dra. Diana (mãe-pai) e Dr. Hess (pai-mãe). Por questões circunstanciais, Dr. Hess se traveste de mulher e com a experiência de se tornar mãe possibilitada pela ingestão do medicamento Engravidol, passa a se comportar de acordo com os estereótipos femininos maternais.

Atenção para o fato de que, no filme, apenas ao homem foi permitido performatizar comportamentos tidos como femininos, enquanto esse tipo de performance não foi franqueado à Dra. Diana, que se comportou dento dos padrões ocidentais e patriarcais esperados para ela. A performatividade atesta que as identidades são culturalmente construídas, flutuantes e cambiantes, não fixas. Essa situação influencia o comportamento humano, tornando o gênero desvinculado do sexo-como-matéria e do sexo-como-instrumento-de-significação-cultural. ${ }^{26}$

Portanto, ser mulher é tronar-se mulher, mas como esse processo nada tem de fixo, é possível tornar-se um ser que nem a categoria socialmente construída de homem nem a de mulher descreve verdadeiramente, como é o caso do comportamento do Dr. Hess ao longo do filme. 
A questão que fica é: contrariando a teoria psicanalítica freudiana de que a mulher é caracterizada como um homem falho, marcada pela falta do falo, no caso do filme Júnior (1994). não seria o homem também falho e invejoso perseguido pelo desejo que lhe foi negado, o de gerar uma vida? ${ }^{27}$ Centrando agora na figura da Dra. Diana, ela é pesquisadora já renomada no meio científico. Tem financiamento para suas pesquisas de criogenia, e por ter prestígio e fomento, recebe o laboratório que era de Dr. Hess e Dr. Arbogast para desenvolver seus experimentos.

Estudos sobre a representação da ciência e de cientistas na mídia, em especial no cinema, não são novidade. Na concepção da maior parte da população leiga, o pesquisador é do sexo masculino, trapalhão genial, cheio de tiques, ridicularizado e incompreendido por seus alunos e pares. ${ }^{28}$ Dra. Diana é desajeitada, e não se preocupa em parecer sensual em sua rotina. Quando se arruma para uma festa, se atrapalha com as saias e os saltos.

Schiebinger ${ }^{9}$ traça um panorama interessante sobre as mulheres dedicadas às ciências, que muitas vezes abdicam dos cuidados com sua aparência, tal como Marie Curie, sempre vista em público com um vestido negro simples e cabelos severamente presos. Na mesma linha, a química Geri Richmond confessou ter abdicado da vaidade para ganhar credibilidade científica pelos seus pares (homens), e Anne Kinney, astrônoma da NASA, se viu forçada a deixar de proferir palestras com vestidos e passou a discursar vestida de jeans e blusa de xadrez, pois sentia como se sua aparência chamasse mais atenção do que sua fala, fato que ocorria com frequência. Sendo assim, ou a mulher precisa forçosamente se livrar da vaidade, quer seja por meio da mimetização de uma atitude masculina, a fim de ser compreendida pelos outros membros da academia, quer seja pela estratégia de concentrar a atenção em suas contribuições científicas, e não na sua beleza física. Mesmo que a Dra. Diana (mãe-pai) esteja em princípio mimetizando atitudes masculinas, ela se deixa levar pelo romantismo e se casa com Dr. Hess, pai-mãe da sua filha.

\section{Mulheres negras - afroamericanas}

Os dois últimos filmes a serem aqui apresentados (Professor aloprado - 1996 e Sem Sentido 1998) trazem em comum a representação da comunidade negra americana. Impossível abordar o assunto sem que se pense nas questões não somente de subalternidade feminina, mas também a segregação racial.

Interessante notar que os dois filmes foram dirigidos por cineastas brancos (Professor aloprado, dirigido por Tom Shadyac, e Sem sentido, por Penelope Spheeris - mulher e branca). Esse fato, por si só, apresenta duas situações interessantes: a representação fílmica de negros sob a perspectiva dos brancos e a visão de uma cineasta branca sobre a condição dos negros e das mulheres retratadas no filme. 
Outro fato curioso é que o filme Professor aloprado, estrelado por Eddie Murphy em vários papéis simultâneos, é uma refilmagem e adaptação do filme Professor aloprado de 1963, estrelado por Jerry Lewis. Nota-se que a representação do que era inapropriado em 1963 para um homem (franzino, tímido, desajeitado) se modificou com o tempo, acompanhando o crescente apelo consumista da sociedade americana capitalista, em que o protagonista do filme de 1996 é obeso, guloso e por isso, também desajeitado como o do filme de 1963.

Mesmo que esses dois filmes sejam os mais recentes dos cinco escolhidos para se utilizar em sala de aula, a participação das mulheres é bem menos expressiva do que nos outros três filmes cronologicamente anteriores. As mulheres estão na trama, de fato para completar o sentido do enredo, mas desempenham seus papéis de forma absolutamente passiva. Fazem com que os homens, protagonistas das histórias, tomem as rédeas da situação, tanto para conseguir conquistar seu objeto de desejo, as pretensas namoradas, como para protegê-las (as mães). Isso demonstra que o male gaze ainda se perpetua, mesmo em filmes de comédia mais recentes. As mulheres negras representadas nos filmes (aspirantes à esposa ou as mães) vêm de origens distintas e são todas redimidas pelo casamento ou maternidade da mesma forma que outras personagens femininas são referidas por Kaplan. ${ }^{16}$

Alguns mecanismos podem explicar a hierarquização e subalternidade das mulheres negras retratadas nesses dois filmes: pela perspectiva psicanalítica, por serem consideradas como "o outro", não homem, não branco, pois aparecem no filme como coadjuvantes do fazer ciência ou fora do espaço científico. Nesse sentido, Buttler ${ }^{26}$ reforça que o sexismo, a homofobia e o racismo seriam o repúdio de corpos em função de seus sexos, sexualidade e/ou cor. Seria uma "expulsão" seguida por uma "repulsa" que fundamenta e consolida identidades culturalmente hegemônicas em eixos de diferenciação de sexo/raça/sexualidade. A operação da repulsa pode consolidar "identidades" baseadas na instituição do "Outro", ou do conjunto de Outros, por meio da exclusão e dominação.

Existe uma conexão direta e permanente entre a manutenção da supremacia branca patriarcal na sociedade e a institucionalização através de meios de comunicação de imagens específicas, diligências de raça, de negritude que sustentam e mantêm a opressão, exploração e dominação global de todas as pessoas negras. Desde a escravidão, a supremacia branca reconheceu o controle sobre as imagens como fundamental para a manutenção de qualquer sistema de dominação racial. ${ }^{29}$

O movimento feminista estadunidense não emergiu de mulheres vitimizadas pela opressão sexista, mas a partir de mulheres brancas pertencentes à burguesia que reivindicavam igualdade social com os homens. Elas, em seu discurso antiopressor, ignoravam a existência de todas as mulheres pobres e não brancas. As feministas do passado não davam atenção e negavam a hierarquia existente entre raça e classe social. Com o passar do tempo, a atitude foi se modificando no sentido de serem mais condescendentes com as mulheres pobres e não brancas, permitindo que estas tomassem parte dos movimentos e das teorizações, como se ambos fossem pertencentes às 
classes brancas burguesas e as outras seriam meras expectadoras visitantes. Aqui se caracterizam a hierarquização e subordinação entre o grupo de mulheres, teoricamente tidas como um bloco único e homogêneo. ${ }^{30}$

Finalmente chegando aos filmes: O professor aloprado (1996) é ambientado em uma cidade não identificada, aparentemente de interior, em que a sociedade é conservadora. O protagonista do filme, Dr. Klump, gordo e tímido, é professor de uma escola secundária e desenvolve uma pesquisa de reordenamento genético que faz suas cobaias emagrecerem rapidamente. Ele se apaixona por uma professora de Química novata na escola, Karla Purdy (Jada Pinkett Smith), admiradora de suas pesquisas. Intimidado por sua aparência física, ele resolve experimentar em si mesmo o produto que acaba por transformá-lo em Buddy Love, que além de magro é mais viril, o que resulta em sua alternância entre períodos de Dr. Jekyll e Mr. Hyde.

O filme mostra homens e mulheres, brancos e negros ocupando de maneira igualitária a sala de aula. Há também mulheres no laboratório onde o Dr. Klump desenvolve seu experimento, mas há maior destaque para seu assistente - homem e branco. O diretor da escola onde a história se passa é também um homem branco. No campo científico, reportando-se à formação de maior graduação, as mulheres se deparam com o "teto de vidro", o que as impede de avançar na formação científica até o topo, pois essas posições são quase sempre destinadas aos homens brancos. Embora nos filmes elas estejam lá, não ocupam os principais postos. ${ }^{21}$

Dr. Klump vem de uma família tradicional de classe média do interior estadunidense, constituída de avó, pai, mãe, irmão e sobrinho, vivendo juntos na mesma casa. A mãe de Klump (também protagonizada por Eddie Murphy, assim como os outros membros da família, excetuandose o jovem sobrinho) é uma mãe tradicional, superprotetora que está sempre presente para ampará-lo e admirá-lo por suas façanhas científicas. Nesse contexto, a mãe é representada como "fora" do âmbito da sexualidade, de maneira não ameaçadora para o homem, iconicamente, ao gosto do patriarcado, como presença doméstica perfeita e integralmente abnegada ao serviço e dominação do pai.

Já Karla Purdy é professora de Química que já conhece e admira o trabalho de Dr. Klump. Ela não somente é objeto de desejo do Dr. Klump, mas toda a trama do filme se desenrola ao redor do processo de sua conquista pelo desajeitado professor. Ela assiste passivamente a todas as ações do filme (bullying pelo qual o professor passa, a autoexperimentação com a droga inovadora, a revelação de todo o mal-entendido decorrente das situações expostas). Aparentemente, não desenvolve nenhum trabalho científico de relevo, ficando a seu encargo somente lecionar e reproduzir o que já está posto no campo científico. Também não são mostrados de forma clara no filme outros professores, mas ao que parece é uma escola mista, em que se aceitam homens e mulheres, brancos e negros. No seu caso, além de sofrer com as barreiras invisíveis da ascensão científica por ser mulher, soma-se o fato de ela ser negra, já que conforme expusemos anteriormente, 
embora a escola pareça oferecer oportunidades iguais para todos, as posições de destaque parecem ser prioritariamente ocupadas por homens brancos.

O conceito da interseccionalidade cunhado por Patrícia Hill Collins ${ }^{31}$ pode oferecer uma explicação para a condição de Karla no filme. O conceito refere-se a uma forma de se pensar e interpretar diferentes dimensões sobrepostas, tais como raça/gênero, gênero/classe, classe/raça, entendendo que as diferentes esferas podem apresentar diferentes pesos e formas de opressão. Não há referências, no filme, a se ela está nessa condição por escolha própria ou por falta de acesso, mas fica claro que a subalternidade científica é iniciada pelo fato de a direção da escola ser exercida por um homem branco; a possibilidade de experimentação em laboratório é conferida a um professor negro; e a sala de aula é oferecida aos dois professores negros, sendo atribuição da mulher apenas lecionar.

Já o filme Sem sentido (1998) é ambientado em Nova York, cidade onde coexiste todo o tipo de pessoas, com diversas culturas, supostamente um ambiente de convívio igualitário. Curiosamente, a obra foi dirigida por uma mulher branca, Penelope Spheeris, sem que isso, no entanto, desse alguma visibilidade às mulheres, brancas ou negras em seu filme. Elas estão lá apenas como coadjuvantes, pois se fossem excluídas não faria a menor diferença na consecução dos eventos principais. Nem mesmo o interesse do protagonista por uma mulher motivou a trama principal. E, de fato, a proposta da comédia não é essa, mas colocar em xeque a ambição desmedida na ascensão social insuflada por uma sociedade ocidental capitalista.

Para melhor entendimento, segue o enredo do filme: Deryll (Marlon Wayans) é o filho mais velho de uma mulher negra e pobre, moradora do Harlem, que foi abandonada pelo marido com cinco filhos para criar. Ele é aluno de uma universidade e faz todo tipo de trabalho para conseguir pagar seu curso de Economia e sustentar a família. Um dos trabalhos que ele aceita e melhor irá remunerá-lo é ser cobaia paga do desenvolvimento de uma droga que aguça todos os sentidos. Ao mesmo tempo, surge um processo seletivo para ser analista júnior em Wall Street. Ele inicialmente foi excluído da competição por conta de sua condição econômica e social, mas retoma a disputa trapaceando e se beneficia dos superpoderes conferidos pela droga experimental, passando a viver todo o tipo de efeito colateral que o experimento pode causar.

Como se pode observar, até mesmo no enredo do filme as mulheres não têm participação direta nos principais eventos, nem mesmo Janice (Tamara Taylor), mulher por quem Deryll se apaixona, é mencionada. O romance entre os dois aparece apenas como pano de fundo.

Esse filme em especial tem vários aspectos que o diferem dos que foram abordados até então. O personagem principal não é o cientista, mas a cobaia. Não há autoexperimentação, mas Deryll (estudante de Economia) se vende para o experimento, assim como para outras atividades (vende esperma, sangue, cabelos). Janice, sua namorada, estuda Literatura na mesma universidade. Eles não fazem parte do mundo laboratorial. 
Quanto à presença das mulheres nas ciências e na academia, o filme mostra salas de aula com frequência praticamente equilibrada entre homens e mulheres, brancos e negros, porém no laboratório em que ocorre a experimentação o pesquisador que coordena o experimento e sua assistente são brancos. Mesmo que nos Estados Unidosos negros estejam socializados no sistema educacional da supremacia branca, muitos estão convencidos de que são indignos de ascender em campos de conhecimento mais complexos. ${ }^{29}$ Quando, ao final do filme, aparece a disputa entre os seis alunos finalistas pela vaga em Wall Street, há apenas uma mulher (branca), que é eliminada logo na primeira fase da competição. Não surpreende que tal fato tenha sido ilustrado no filme, e revela uma realidade americana da época.

Em fins dos anos 1980, início dos anos 1990, a estatística americana Betty Vette apontou que de cada dois mil meninos do nono ano e duas mil meninas do mesmo nível educacional, mil de cada grupo obtinham formação suficiente em matemática para prosseguir os estudos em Ciências Exatas. No fim do ciclo secundário, apenas 280 dos homens e 210 das mulheres teriam formação matemática suficiente para seguir uma carreira técnica. ${ }^{9}$ Embora o estudo não tenha se aprofundado em descobrir o porquê desses números, nem provavelmente Penelope Spheeris tenha neles se baseado ao dirigir o filme, pode vir daí, de uma interpretação simplista e superficial de dados numéricos, o senso comum em se representar no filme apenas uma mulher nas finais de uma disputa que dependa de conhecimentos matemáticos.

A participação das mulheres nessa trama é de fato pequena, embora o filme tenha sido dirigido por uma mulher. Há duas personagens femininas de maior destaque: a mãe de Deryll, que sequer tem nome pronunciado no filme, e Janice a namorada. Janice é negra, filha de um empresário branco e uma negra, o que lhe atribui outro estrato social. Com isso, ela teve a oportunidade de frequentar a Faculdade de Literatura, curso de sua escolha, contrariando a vontade do pai, que desejava para ela a cadeira de Direito. A participação dela no enredo é pequena, fechando apenas o par romântico desejável para a empatia do público com o filme.

Na época em que o filme foi produzido, a discriminação ostensiva na academia nos Estados Unidos já havia amenizado, pois era perfeitamente admissível a segregação racial nas universidades até os fins dos anos de 1960 e início dos anos de 1970, por exemplo. Constrangimento duplo era experimentado por mulheres negras, ${ }^{9}$ o que não aparece no filme. Já a mãe de Deryll, embora tenha inicialmente criado os filhos sozinha, agora depende dele para garantir o sustento da casa e a criação dos irmãos menores.

No início, a grande luta das mulheres negras era a oposição ao racismo, em primeiro lugar, situação opressora tanto para homens como para mulheres. O objetivo dessa luta era a igualdade nas estruturas sociais existentes, para garantir sobrevivência digna, já que a maioria das pessoas que reivindicavam eram pobres e viviam em bairros racialmente segregados. ${ }^{29}$ Os papéis de gênero para as mulheres negras nessa condição eram, portanto, mais claramente definidos como mães e 
donas de casa, e elas viviam na base da cadeia de opressão, inclusive nos movimentos feministas americanos: homens e mulheres brancos que oprimem todos os negros, seguidos de mulheres brancas e homens negros que oprimem mulheres negras. ${ }^{30}$

O que se nota no filme, então, é a supremacia masculina sobre todas as ações. O protagonista é ridicularizado durante toda a história, embora em alguns momentos ele ressalte o pensamento vigente de sua raça, pelo fato de ser negro (não de maneira descabida, afinal trata-se de uma comédia). Mesmo que este seja o filme mais recente dentre os cinco selecionados e tenha sido dirigido por uma mulher branca falando de negros, fica aqui a percepção de que, embora os anos passem, a passividade feminina representada nos filmes de Hollywood continua a ser perpetuada, pois aqui elas passam praticamente despercebidas, como objeto de admiração ou de prazer, sob o male gaze dos espectadores homens e brancos.

\section{Depois de tudo}

Os filmes de comédia abordados podem funcionar como ferramenta útil para o aporte do ensino de Deontologia Farmacêutica, tanto de maneira objetiva, tratando especificamente dos temas inerentes à disciplina, como no sentido de ampliar as discussões que podem surgir a partir de um olhar mais profundo sobre as obras, tomando como premissa a formação humanística de um aluno crítico e reflexivo.

Os cinco filmes em questão: "The monkey business" (O inventor da mocidade, 1952); "The nutty professor" (O professor aloprado, 1963); "Junior" (Júnior, 1994); "The nutty professor" (O professor aloprado, 1996) e "Senseless" (Sem sentido, 1998) foram assistidos e analisados pelas quatro turmas ao longo dos anos de 2012 e 2013, sendo que os alunos se restringiram a responder a um roteiro analítico proposto que levava em consideração apenas as questões operacionais da disciplina, cabendo pouco ou quase nenhuma apreciação fora desse escopo por parte das turmas observadas, mesmo que esse espaço tenha sido aberto para eles.

Isso provavelmente se deve ao fato de que a disciplina conta com pequena carga horária frente ao total do curso, de formação majoritariamente tecnicista e instrumental. O fato é que a exclusão das mulheres do campo científico, evidente em todos os filmes, não foi sequer questionada pelos alunos, em sua maioria mulheres (71 alunas num total de 83). Coube à docente da disciplina sinalizar em todas as turmas e fazer comentários relacionados aos filmes e aos referenciais teóricos adequados a cada situação. Isso nos leva a crer que, mesmo que as mulheres tenham conseguido avanços sociais por intermédio de movimentos políticos, sua subalternização é tão arraigada no senso comum, que até mesmo potenciais cientistas (alunas de graduação na área da Saúde) naturalizam essa ausência, não reconhecendo um lugar que também é seu por direito. 
Os pontos dos filmes assinalados nas turmas durante a apresentação do estudo de caso levaram em consideração o espaço temporal em que os filmes foram concebidos. Essa situação faz toda a diferença para se entender a maneira pela qual as personagens femininas foram representadas e analisadas, tendo em vista que: em 1952 (O inventor da mocidade), o ideal da imagem feminina era a "rainha do lar"; em 1963 (O professor aloprado), já havia a permissão da sexualidade para as mulheres, que nem por isso deixavam de ser "boazinhas". Nesses dois primeiros títulos, o male gaze é sem dúvida mais presente. Em 1994 (Junior), a total inversão de papéis permitiu que um homem fosse mãe, cabendo explicar esse comportamento pelo conceito de performatividade proposto por Judith Buttler; e finalmente, em 1996 e 1998 (O professor aloprado e Sem sentido), aparecem na academia, mesmo que de maneira secundária, mas ainda persistem as condições de desigualdade mais profunda sentidas pelas mulheres negras.

Assim, as mulheres aparecem como coadjuvantes do fazer ciência ou coadjuvantes das histórias, assumindo posição passiva: em $O$ inventor da mocidade, Edwina é sujeito da experimentação do marido; em O professor aloprado de 1963 e 1996, Stella é aluna e Karla é professora assistente; em Junior, embora Diana seja pesquisadora, ela é par romântico do Dr. Hess; e em 1998, Sem sentido, Janice é apenas objeto de desejo do protagonista. Mesmo que o tempo tenha passado e transformações sociais tenham ocorrido, os velhos estereótipos ainda permanecem, ainda que de maneira mais velada.

Todos os fatos aqui expostos serviram para uma reflexão mais profunda em sala de aula, não só sobre o papel do pesquisador de substâncias terapêuticas, como também do lugar da mulher no campo científico. A prática pedagógica proposta e aqui ampliada demonstra que a interseção Ciência \& arte é promissora para despertar discussões importantes, desde que seja tomado o cuidado, por parte do docente, em aprofundar seus argumentos. Assim o cinema de comédia pode contribuir para transcender questões inerentes apenas da disciplina e promover uma formação mais completa do aluno, mostrando que a mulher, e neste caso específico, a farmacêutica, também pode ser protagonista do "fazer ciência".

\section{Agradecimentos}

Ao apoio financeiro da CAPES no programa PDSE* (Programa de Doutorado Sanduíche no Exterior), processo BEX 14355/13-2, e às professoras Adriana Conceição Silva Pereira Bebiano Nascimento e Maria Irene Ramalho, orientadoras do Programa de Doutoramento em Estudos Feministas da Universidade de Coimbra, Portugal. 


\section{Referências}

1. Sousa FC. Ética e deontologia: textos para profissionais atuantes em bibliotecas. Florianópolis: Editora UFSC; 2002.

2. Batista MM. Estereotipia e representação social: uma abordagem psicossociologia. In: Barker DA, organizador. O poder e a resistência dos estereótipos. Aveiro: Universidade de Aveiro; 2004, p. 103-116.

3. Arruda A. Teoria das representações sociais e teorias de gênero. Cadernos de Pesquisa 2002; 117(127):127-147.

4. Tega D. Mulheres em foco: construções cinematográficas brasileiras da participação política feminina. São Paulo: Cultura Acadêmica-UNESP; 2010.

5. Cruz AL. O olhar predador: a arte e a violência do olhar. Estudos feministas e cidadania plena. Revista Crítica de Ciências Sociais [Internet] 2010; 89. [acesso em: 14 maio 2014]. Disponível em: https://rccs.revues.org/3685?lang=es\#tocfrom1n1

6. Keller EF. Qual foi o impacto do feminismo na ciência? Cadernos Pagu 2006; (27):13-34.

7. Costa MC. Ainda somos poucas: exclusão e invisibilidade na ciência. Cadernos Pagu 2006; (27):455-459.

8. Chassot A. A ciência é masculina? É sim senhora. Vale dos Sinos: UNISINOS; 2011.

9. Schiebinger L. O feminismo mudou a ciência? Santa Catarina: EDUSC; 2001.

10. Cozzi ALF. As personagens femininas em Macunaíma: sexualidade e gênero no modernismo pós-1922. $5^{\circ}$ Prêmio Construindo a Igualdade de Gênero. Redações, artigos científicos e projetos pedagógicos vencedores. Brasília: Presidência da República, Secretaria de Políticas para as Mulheres; 2010. p. 83-103.

11. Nogueira P. A ciência das mulheres. UNESP Ciência 2011; (17):18-25. [acesso em: mar 2013]. Disponível em: http://www.unesp.br/aci_ses/revista_unespciencia/acervo/17/a-ciencia-das-mulheres.

12. Henriques MF. Concepções filosóficas e representações do feminino: subsídios para uma hermenêutica crítica da tradição filosófica. Estudos feministas e cidadania plena. Revista Crítica de Ciências Sociais jun 2010; 89. [acesso em: 12 abr. 2014]. Disponível em: http://rccs.revues.org/3661.

13. Ramalho MI. Difference and hierarchy revisited by feminism. Anglo Saxonica 2013; III(6):23-45. [acesso em: 12 abr. 2014]. Disponível em: http://www.ulices.org/images/site/pdfs/ASaxoIII-N6a.pdf

14. Corrêa VSA. Gestão escolar e gênero: o fenômeno do teto de vidro na educação brasileira [Dissertação]. Curitiba: Universidade Federal do Paraná. Pós-graduação em Educação 2010.

15. Mulvey L. Visual pleasure and narrative cinema. Screen 1975; 16(3):6-18. [acesso em: 15 maio 2014]. Disponível em: http://www.jahsonic.com/VPNC.html.

16. Kaplan A. A mulher e o cinema: os dois lados da câmera. Rio de Janeiro: Rocco; 1983.

17. Blainey G. Uma breve história do século XX. São Paulo: Fundamento; 2008.

18. Narvaz M, Koller SH. Metodologias feministas e estudos de gênero: articulando pesquisa, clínica e política. Psicologia em Estudo 2006; 11(3):647-654. 
19. Federação Nacional dos Farmacêuticos. Campanha sou mulher, sou farmacêutica, tenho direitos! São Paulo: FENAFAR; 2012. [acesso em: 29 maio 2014]. Disponível em: http://www.fenafar.org. br/pdf/livreto-mulher.pdf.

20. Irigaray L. Entrevista: poder do discurso/Subordinação do feminino. Transcrito por Catherine Porter. ex-aequo 2003; 8:45-55.

21. Araújo DB. A ciência e as relações de gênero. Estudos IAT 2010; 1(1):4-17.

22. Hobsbawn E. Era dos extremos: o breve século XX - 1914-1991. São Paulo: Companhia das Letras; 1994.

23. Maffia D. Crítica feminista à Ciência. In: Costa AAA, Sardenberg CMB, organizadores. Feminismo, ciência e tecnologia. Salvador: REDOR/NEIM-FFCH/UFBA; 2002. p. 25-39.

24. Silva RA. Estereótipos na ficção cinematográfica: a representação da cientista no filme Contato. Intercom - Sociedade Brasileira de Estudos Interdisciplinares da Comunicação, XXX Congresso Brasileiro de Ciências da Comunicação, Santos; 29 ago - 2 set 2007.

25. Cunha MB, Giordan M. A imagem da ciência no cinema. Química Nova na Escola 2009; 31(1):9-17.

26. Buttler J. Gender Trouble: feminism and the subversion of identity. New York: Routledge; 1990.

27. Le Breton D. Adeus ao corpo. Antropologia e Sociedade. Campinas: Papirus; 2003.

28. Barca L. As múltiplas imagens do cientista no cinema. Comunicação \& Educação 2008;10 (1):31-39.

29. Hooks B. Black looks: race and representation. Boston: South end Press; 1992.

30. Hooks B. Feminist theory. from margin to center. Boston: South end Press; 1984.

31. Sardenberg CMB. Da crítica feminista à uma ciência feminista. In: Costa AAA, Sardenberg CMB, organizadoras. Feminismo, ciência e tecnologia. Salvador: REDOR/NEIM-FFCH/UFBA; 2002. p. $89-120$.

Recebido: 13/4/2016

Revisado: 27/7/2016

Aceito: $12 / 8 / 2016$ 
